\title{
PER UNA SOCIOLOGIA DE LA FAMILIA A CATALUNYA
}

\author{
Luís Flaquer \\ (Universitat de Barcelona)
}

Aquest article constitueix un intent de plantejar els principals problemes que suscita l'estudi de la família catalana des d'un punt de vista sociològic. Després de fer un breu repàs a les escasses publicacions sobre el tema, l'autor proposa un marc teòric dins el qual es puguin inscriure les futures investigacions i enumera un catàleg de qüestions que mereixen un tractament aprofundit en un estudi sobre la família a Catalunya. L'article comença analitzant els problemes plantejats per l'estructura i el volum de les llars, i passa tot seguit a completar aquest enfocament a base d'examinar el cicle evolutiu dels grups domèstics. L'última part de l'article és dedicada a estudiar la telació existent entre eis rols conjugals d'una família i l'ambient social que l'envolta, i proposa una hipòtesi per a relacionar ambdós termes. 


\section{Introducció}

Malauradament la sociologia de la familia a Catalunya no ha estat gaire afortunada. Tanmateix, els sociởegs catalans, que per raons imperatives força òbvies han esmerçat tant de temps i esforços, pet exemple, en la sociologia urbana, la de l'educació i la de les migracions, han oblidat gairebé del tot el fet familiar. Aquesta situació és encara més paradoxal quan veiem que moralistes i profetes de totes menes, de dreta i d'esquerra, clamen al cel escandalitzats davant la crisi de la família i dels costums o bé auguren una fi molt propera a la institució farniliar. L'autor d'aquest treball creu que ja és hora de bandejar discursos i especulacions ideològiques i de començar a laborar per tal de substituir-los per evidències empíriques.

En aquest article, primer de tot, intentaré de fer una breu referència al que sabem sobre la família catalana, que és ben poc, per oferir tot seguit un marc teòric dins el qual puguem emmarcar les futures investigacions sobre la família a Catalunya. En aquest sentit, l'article serà més aviat programàtic i constituirà un catàleg de problemes i enfocaments que, a judici de l'autor, són les àrees d'investigació primotdials en l'esdevenidor.

El primer problema que se'ns planteja és què entenem per família i quines qüestions haurien de quedar incloses dins una sociologia de la família. La primera pregunta sembla ociosa, però, de fet, la seva resposta comporta greus implicacions quant a la delimitació del camp de la sociologia de la família i quant a les perspectives teòriques escollides.

Parlar de la sociologia de la família i no del parentiu, per exemple, com solen fer els antropòlegs, suposa $j a$ donar una certa preeminència $i$ autonomia a la família nuclear, $i$ deixar en segon terme les relacions de parentiu que existeixen entre les diverses unitats conjugals.

Hi ha nombrosos estudis estratificacionals, de sociologia urbana, etc., que empren la família i no l'individu com a unitat d'anàlisi (partint de la suposició que la mullex $\mathrm{i}$ els fills pertanyen a la mateixa classe o status 
que el cap de família). Ningú no negarà la comoditat d'aquest artilugi, però també és evident que d'aquesta manera molts estudis poden ésser considerats com a part de la sociologia de la família. En les pàgines que segueixen passarem revista a les qüestions que, al meu parer, haurien de constituir lobjecte primordial de la sociologia de la família.

La primera constatació que cal fer és que «família» es un terme polisèmic que, com molt bé assenyala Goody, ${ }^{1}$ es pot referir a una multiplicitat d'entitats, com una parella $i$ els seus fills, els membres d'una llar, un conjunt de familiars o bé a un grup patronímic o un llinatge. Pet això, moltes vegades és convenient afegir un atribut al terme familia per precisar el seu significat, com quan parlem de família conjugal o nuclear, troncal, extensa, família d'orientació i procreació, etc. Per evitar aquests confusionismes parlaré sovint al llarg de l'article de grup domèstic residencial o bé simplement de llat (bousebold, anglès; ménage, francès) en lloc de família tout court.

Crec que podrem aprendre moltes coses sobre l'estructura de la famí lia a base d'analitzar el cens i els padrons municipals, i les «famílies» que hi trobem són en realitat «llars», unitats residencials i no unitats de procreació i de filiació. Aquest fet té certs avantatges, però evidentment comporta importants conseqüències teòriques. Tanmateix, crec que hom pot acceptar, doncs, que la unitat d'anàlisi inicial d'un estudi sobre la família ha d'ésser la llar per raons d'utilitat.

\section{Breu balanç dels estudis familiars a Catalunya}

Ja he dit al principi d'aquest article que és ben poca cosa el que sabem sobre l'estructura i el funcionament de la familia catalana.

Gràcies a diversos estudis empresos per antropòlegs comencem a conèixer quelcom de la família zural catalana i concretament de la pairal." Com és usual en la recerca antropològica, aquests coneixements s'han obtingut mitjançant el treball de camp en petites comunitats i per tant no posseim estudis estadístics que permetin de generalitzar aquestes observacions.

El que sabem sobre la família urbana catalana és encara més poc. Les minses dades que tenim són observacions escadusseres que apareixen en

1. Jack Goody, «The evolution of the family», pp. 103-124, en P. Laslett (1972), p. 103.

2. Vegeu especialment Ignasi Terrades (1971); J. Prat (1973); J. Frigolé (1974); Françoise Breton i Lorea Barnuti (1978). 
publicacions d'àmbit estatal sobre la família o l'estructura social espanyola. ${ }^{3}$

Davant aquest lamentable estat de coses cal proposar un pla de recetca en el qual es reflecteixi un inventati de les qüestions més debatudes en el camp de la sociologia de la família. En suma, cal preguntar-nos què és el que no sabem sobre la família catalana, quins són els aspectes que més interessa conèixer per les implicacions que tenen en la sociologia de la família $i$ en altres camps i disciplines, $i$ com podem obtenir aquests coneixements. Això és el que em proposo de fer en la resta de l'article.

Per això, començarem examinant el volum i l'estructura de les llars, per passar tot seguit a l'anàlisi del cicle evolutiu del grup domèstic, a l'estudi dels rols dels membres de les llars i les relacions que mantenen entre ells, i per acabar parlant de la relativa autonomia de la familia nuclear actual.

\section{El volum i l'estructura de les llars}

Qualsevol consideració del fet familiar ha de partir de l'examen del nombre dels membres que les unitats residencials presenten en un temps i un espai donats. $\mathrm{El}$ volum de les llars és evidentment funció del nombre de fills que té una parella, petò també, en famílies de tipus més tradicional, del nombre de parents i servents que viuen sota un mateix sostre amb el nucli familiar. A causa d'aquest fet, no n'hi ha prou de conèixer la mitjana aritmètica dels membres de les liars per municipis o comarques, sinó que també cal esbrinar l'estructura d'aquests grups domèstics. Per estructura entenem les relacions de parentiu o d'altres que existeixen entre llurs membres.

La qüestió de la determinació de les estructures residencials predo. minants en una societat donada s'inscriu dins un debat teòric els termes del qual procuraré de resumir breument. En el nostre cas, les dues estruc. tures que més ens interessen són la nuclear (una parella amb els seus fills petits, sense casar) i la troncal (una sola parella amb eis seus fills petits a cada nivell generacional).

Fou Frédéric Le Play (1871) qui primer encunyà el terme «familia troncal» (famille-souche) i qui primer descrigué aquesta estructura familiar residencial. Segons Le Play, el model troncal, que ell trobà a les regions meridionals de França, era la millor forma d'organització familiar i calia

3. Vegeu especialment Instituto de Sociología Aplicada de Madrid (1976); Fundación FOESSA (1970); Antonio de Pablo Masa, «La familia española en el cambion, pp. 149-187 en Fundació FOESSA (1978). 
defensar-lo a tota ultrança contra els embats de les noves estructures que s'anaven estenent, com ara la nuclear.

Els teòrics de la modernització vénen a dir que una de les conseqüències de la industrialització és la progressiva desaparició de les famillies extenses, de les quals la troncal és una variant, i la seva substitució gradual pel model nuclear, més adaptat a la societat industrial. Si aquesta teoria fos certa, doncs, la família troncal catalana, típica de la Catalınya Vella, estaria destinada a desaparèixer amb els avenços de la urbanització i la industrialització, $i$ un dels graus de modernitat seria precisament la proporció elevada de famílies nuclears en una societat determinada amb el consegüent baix percentatge de families esteses, en el nostre cas troncals. Petò la paradoxa rau precisament en el fet que les dues úniques regions de l'Estat espanyol on trobem estructures troncals, Catalunya i el País Basc, són els dos únics paiisos que es van industrialitzar ja des del segle XIX. Alguns autors, com J. Vicens Vicens (1960), fins i tot arriben a establir una relació entre industrialització i sistema successori d'herència indivisible, estretament lligat amb la familia troncal en el cas català $i$ basc.

Per si les coses no fossin prou complicades, P. Laslett i els seus collaboradors del Cambridge Group for the History of Population and Social Structure en una sèrie de publicacions $(1965,1972)$ han tirat per terra la teoria de la modernització acceptada funs ara unànimement. Segons Laslett, no és possible que la família nuclear fos resultat de l'erosió de les estructures extenses per la industrialització, perquè gràcies a les seves troballes ha establert d'una manera rotunda i defnitiva que a tota l'Europa occidental i septentrional d'ençà del segle xvrr (des de l'existència de documentació sobre el volum i la composició de les llars) existia ja el model nuclear. Així, doncs, la industrialització no pot haver estat la causa de la disgregació de les estructures extenses en nuclears, puix que aquestes ja existien abans de la Revolució Industrial. D'altra banda, Laslett en les seves recerques no ha sabut trobar famillies troncals en les regions que ha investigat, si bé és cert que d'altres historiadors de la familia, com L. Berkner (1972), W. L. Parish i M. Schwartz (1972) i A. Fine-Souriac (1978), cercant sobretot en les zones meridionals i orientals d'Europa han pogut documentar àmpliament la seva existència.

Seria, doncs, també interessant poder documentar estadísticament a la Catalunya Vella rural la clara implantació de llars de tipus troncal des de fa uns quants segles. Aquesta confirmació significaria una notable aportació i un contracàs per a la teoria de Laslett, ja que aquest suposa implí. citament -a falta de proves- que la família nuclear és una de les precondicions de la industrialització.

El Cens de 1970 dóna per províncies, i per mitjà rutal i urbà, una 
classificació de les llars segons els epígrafs següents; «llars sense nucii familiar», «família nuclear reduïda», «família nuclear nombrosa», «família nuclear ampliada» i «famfllia plurinuclear». D'aquestes estructures són les dues últimes les que més ens interessen de cara a la determinació de l'existència de famílies troncals a Catalunya. Segons les dades proporcionades pel Cens a la zona rural de Catalunya i les Illes, un $12,2 \%$ de les llars són plurinuclears (famílies troncals pures) i un 17,9\% són famílies nuclears ampliades (clars indicis d'estructura troncal). A més, també caldria saber quina proporció de llars troncals es troben en fase nuclear, cosa difícil d'esbrinar només a partir de les dades del Cens. És per això que en l'estudi de la familia cal introduir un nou concepte, a saber, el cicle evolutiu dels grups domèstics.

\section{El cicle evolutiu dels grups domèstics}

Fins ata hem estat adoptant una perspectiva estàtica o fotogràfica en l'anàlisi dels censos i padrons. Les limitacions d'aquest enfocament ens exigeixen d'introduir una nova dimensió tempozal o cinematogràfica en l'estudi del fet familiar. Tots els nuclis familiars travessen una sèrie de fases o etapes al llarg de llut vida d'existència. Neixen o es creen pel matrimoni; passen per una fase d'expansió quan vénen els fills, es tornen a contraure si marxen els fills ja grans, i es dissolen per la separació o la mort dels esposos. Els nuclis o parelles de les families troncals no escapen a aquesta llei de vida, $i$ és per això, com deia abans, que moltes famílies troncals passen per una fase nuclear. Quan s'analitzen els censos cal tenir en compte aquest fet, com han posat en relleu molt encertadament $L$. Berkner (1972) i A. Fine-Souriac (1978). Altrament el percentatge de famílies nuclears queda engruixit indegudament. Per evitar aquest inconvenient o bé és recomanable d'analitzar diversos censos successius o bé procedir al seguiment d'una mostra de llars al llarg d'un cert període de temps.

Fout Meyer Fortes en una monografia ja clàssica ${ }^{5}$ el qui exposà la necessitat d'aquesta visió diacrònica i creà el concepte de cicle evolutiu dels grups domèstics. Segons aquest autor, cal ésser sensible a la dimensió temporal dels grups domèstics, els quals presenten una evolució cíclica a cada generació. Meyer Fortes distingeix tres estadis en aquest cicle evolutiu. La fase d'expansió dura des del matrimoni de la parella fins a la vinguda de l'úlim fill. Cavalcant sovint amb la fase anterior tenim la fase de dispersió

4. Instituto de Sociología Aplicada de Madtid (1976), p. 42.

5. Meyer Fortes, "Introduction», pp. 1-14, en Jack Goody (ed.) (1958). 
o fissió, que comença amb el matrimoni del fill més gran $i$ acaba quan tots els fills s'ban casat. A partir d'aquest moment s'inicia la fase de reernplaçament, que conclou amb la mort dels pares.

Crec que aquest esquema és prou convenient per examinar la problemàtica que suscita l'estudi de la famflia catalana.

Comencem per la constitució de la família mitjançant el matrimoni. Totes les societats tenen uns camins institucionalitzats que condueixen al matrimoni. Em refereixo, en el cas de Catalunya, al festeig i al prometatge. Sobre aquestes qüestions se'ns plantegen força interrogants. Ens cal saber quines diferències hi ha entre les pautes de prometatge al camp i a la ciutat, entre les diverses classes socials, quir paper hi té l'educació, etc. Els canvis produits en els ûtims temps sobre les normes de festeig i prometatge són prou evidents, però ens en cal un estudi seriós $i$ aprofundit. Per últim, cal veure quines diferències hi ha entre el model de prometatge català i el d'altres regions d'Espanya, d'una banda, i el dels paisos europeus més avanç̧ats, de l'altra.

Igualment ens calen estudiar les estratègies matrimonials que adopten sobretot les classes altes per a la preservació de llurs interessos i privilegis, els nivells d'homogàmia i heterogàmia de la societat catalana (o sia, l'estudi del matrimoni interclassista com un mitjà de mobilitat social vertical) i, per últim, el funcionament del mercat matrimonial."

Pel que fa a la fase d'expansió hom podria estudiar el fenomen del descens de la fecunditat $i$, per tant, del volum de les famílies no tan sols real sinó també ideal.

En la fase de dispersió o fissió es comencen a plantejar els ptoblemes que més tard es resoldran amb la mort dels pares i la successió. Cada societat dóna una solució diferent a la quuestió del repartiment dels béns acumulats per una família. El sistema successori català tradicional era un sistema d'herència indivisible, la qual rebia l'hereu, amb pagament de llegitimes (un quart del patrimoni) als fadristerns o cabalers (fills no hereus). Aquest sistema està lligat al pairalisme i a la família troncal ja descrita, $\mathrm{i}$ caldria veute fins a quin punt no ha entrat ja en crisi a la ciutat $i$ àdhuc al mateix camp de la Catalunya Vella. En tot cas, se'ns torna a plantejar aquí, sota una altra faceta, l'apassionant qüestió de la relació entre el sis. tema successori, la natalitat, la familia troncal, l'elevat grau de celibat, la divisió de la terra i la industrialització."

6. William J. Goods (1964) suggeteix encertadament (cap. 4) que hom consideri el matrimoni un mercat d'unes característiques especials.

7. Per un tractament d'aquests problemes a escala europea, vegeu $\mathrm{H}$. J. Habakkuk (1955). 
Un altre aspecte relacionat amb la dissolució parcial de la família és la sociologia de la separació i el divorci. Encara que el divorci no hagi estat legalitzat, des de fa uns deu anys s'han anat produint nombroses separacions legals $i$ de fet, $i$ els nostres sociòlegs tenen ja una massa considerable de dades per investigar. Caldria saber qui se separa i per què, qüestions aparentment senzilles però prenyades de problemes quant a la seva operativització.

\section{Els rols dels membres de la llar}

Una de les dimensions més interessants de l'estudi de la família és la dels rols masculí i femení dins la llar. Si en les famílies turals tradicionals hi havia una marcada divisió sexual del treball, en les famílies urbanes estem assistint a l'esvaïment de diferències entre les funcions masculina i femenina. Entre aquests dos extrems podríem trobar tota una gamma intermèdia de casos.

Una forma d'estudiar l'evolució dels rols sexuals dins la família en la societat catalana és construir dos models ideals de família que incorporin els trets d'aquestes posicions extremes. La «família tradicional» estaria caracteritzada pel fet d'ésser una unitat de producció, pel seu alt grau de patriarcalisme, per una forta divisió sexual del treball i per l'existència d'unes esferes d'attibucions teservades a cada cònjuge. Al contrari, la «família moderna» presentaria els trets següents: familia com a unitat de consum i no de producció, elevada comunicació entre els dos membres de la parella, una relació més «democràtica» entre pares i fills, presa de decisions conjuntes, indeterminació i intercanvi de tasques domèstiques, dedicació del temps de leure a activitats conjuntes, etc.

Aquests dos tipus ideals podrien servir per confeccionar qüestionaris per utilitzar en una enquesta que tindria per objecte esbrinar, diferencialment, segons l'origen social dels enquestats, quines són les seves actituds i les seves pautes de conducta pel que fa als rols masculins i femenins.

\section{Les relacions dels membres dels grups domèstics amb l'exterior}

La separació que imposen les parets mestres d'una casa pot ésser a vegades més feble que la que imposen els envans d'un pis. Amb això vull dir que les famílies nuclears més autònomes $i$ independents estan influides per les xarxes de parents, amics o veïns que tenen una incidència notable sobre llur funcionament intern. No podríem acabar aquest inventari de 
qüestions sobre la familia catalana sense dedicar unes ratiles a les relacions que mantenen els grups domèstics entre ells i a la influència que tenen aquestes relacions en llur configuració pròpia.

Cal citar en aquest sentit l'estudi capdavanter d'Elisabeth Bott (1957). Aquesta antropòloga estava interessada en la tecerca d'alguna hipòtesi que relacionés els rols dels esposos amb el seu entorn. I heus ací que després d'investigar a fons unes vint parelles, va arribar a la conclusió que els factors que més influien els rols conjugals eten les xarxes socials de la parella. I així va formular la seva coneguda hipòtesi que «el grau de segregació de la relació de tols del marit i de la muller varia directament àmb la connexitat de la xarxa social de la famílias. ${ }^{8}$ Amb això vol dir que una familia que tingui una xarxa força interconnectada, o sia els parents, amics o veìns de la qual es coneguin directament entre ells, serà probablement «tradicional» en el sentit del tipus ideal de l'apartat anterior, mentre que les famílies amb una xarxa inconnexa tendiran probablement a ésser més «modernes» pel que fa a l'execució dels rols masculins i femenins.

Aquesta hipòtesi ha estat posada a prova en nombroses ocasions i contextos, ${ }^{9} \mathrm{i}$ sempre ha donat fruits relativament bons. Aixi, doncs, seria interessant també d'aplicar-la al cas català per veure si pot donar llum sobre la relació entre rols conjugals i ambient social.

El pla que acabo d'esbossar és certament ambiciós i és obvi que només un equip d'investigació amb fons adequats podria portar-lo a terme. A manca d'això, seria convenient qưe joves investigadors anessin treballant en aspectes parcials de les qüestions que assenyalo aquí, en monografies d'àmbit local per anar bastint a poc a poc el nostre coneixement de la institució familiar a Catalunya. Només així serà possible arribar a omplir un buit en una àrea certament estratègica de l'estructura social catalana.

\section{LLuís FLAQuer}

Departament de Sociologia

Universitat de Barcelona (Pedralbes)

Barcelona

8. Elisabeth Bott $(1957)$, p. 60.

9. Per exempie, entre altres, C. Turner (1967) i B. Kapferer (1973). 


\section{REFERENCIES BIBLIOGRAFIQUES}

Lutz K. Berkner, «The stem family and the developmental cycle of the peasant household. An eighteenth century Austrian example», American Historical Review 77 (1972): 398-418.

Elisabeth Bott, Family and Social Network (Londres: Tavistock, 1957).

Françoise Breton \& Lotea Barruti, La família $i$ el parentiu (Barcelona: Dopesa, 1978).

Agnès Fine-Souriac, «A propos de la famille-souche pyrénéenne au XIXe siècle: Quelques réflexions de méthode», Revue d'bistoire moderne et contemporaine 25 (1978): 99-110.

Fundación Foessa, Informe sociologico sobre la situación social de España 1970 (Madrid: Euramérica, 1970).

Fundación Foessa, Sintesis actualizada del III Informe Foessa 1978 (Madrid: Euramérica, 1978).

J. Frigolé, «Estructura social y diferenciación socio-cultural: el sistema matrimonial y la herencia», Etbnica 7 (1974).

William J. Goode, The Family (Englewood Cliffs: Prentice Hall, 1964).

Jack Goody (ed.), The Developmental Cycle in Domestic Groups (Cambridge: Cambridge University Press, 1958).

H. J. Habakkuk, «Family structure and economic change in nineteenthcentury Eutope», The Journal of Economic History 15 (1955): 1-12. 
"Papers»: Revista de Sociologia

Instituto de Sociología Aplicada de Madrid, Estudio sociologico de la familia española (Madrid: Confederación Española de Cajas de Ahorros, 1976).

Peter Laslett, The World We Have Lost (Cambridge: Cambridge University Press, 1965).

Peter Lasiett (ed.), Housebold and Family in Past Time (Cambridge: Cambridge University Press, 1972).

Frédéric le Play, L'organisation de la famille selon le vrai modèle signalé par l'bistoire de toutes les races et de tous les temps (París, 1871).

W. L. Parish, Yr. i M. Schwartz, «Household complexity in nineteenth century France», American Sociological Review 37 (1972): 154-173.

J. Prat, «Estructura y conflicto en Ia familia pairal», Etbnica 3 (1973).

Ignasi Terrades, Antropología del campesino catalán, 2 vols. (Barcelona: A. Redondo, 1971).

C. Turner, «Conjugal roles and social networks: a re-examination of an hypothesis», Human Relations 20 (1967): 121-130.

Jaume Vicens Vives, Noticia de Catalunya (Barcelona: Destino, 1960). 